Article

\title{
Fractal Characterization of Nanopore Structure in Shale, Tight Sandstone and Mudstone from the Ordos Basin of China Using Nitrogen Adsorption
}

\author{
Xiaohong Li ${ }^{1}$, Zhiyong Gao ${ }^{1}$, Siyi Fang ${ }^{2}$, Chao Ren ${ }^{1}$, Kun Yang ${ }^{2}$ and Fuyong Wang ${ }^{2, *(1)}$ \\ 1 Central Laboratory of Geological Sciences, RIPED, PetroChina, Beijing 100083, China; \\ lixiaohong5@petrochina.com.cn (X.L.); gzy@petrochina.com.cn (Z.G.); renchao2018@petrochina.com (C.R.) \\ 2 Research Institute of Enhanced Oil Recovery, China University of Petroleum, Beijing 102249, China; \\ 2017210530@student.cup.edu.cn (S.F.); 2017210531@student.cup.edu.cn (K.Y.) \\ * Correspondence: wangfuyong@cup.edu.cn
}

Received: 31 December 2018; Accepted: 1 February 2019; Published: 13 February 2019

\begin{abstract}
The characteristics of the nanopore structure in shale, tight sandstone and mudstone from the Ordos Basin of China were investigated by X-ray diffraction (XRD) analysis, porosity and permeability tests and low-pressure nitrogen adsorption experiments. Fractal dimensions $D_{1}$ and $D_{2}$ were determined from the low relative pressure range $\left(0<\mathrm{P} / \mathrm{P}_{0}<0.4\right)$ and the high relative pressure range $\left(0.4<\mathrm{P} / \mathrm{P}_{0}<1\right)$ of nitrogen adsorption data, respectively, using the Frenkel-Halsey-Hill (FHH) model. Relationships between pore structure parameters, mineral compositions and fractal dimensions were investigated. According to the International Union of Pure and Applied Chemistry (IUPAC) isotherm classification standard, the morphologies of the nitrogen adsorption curves of these 14 samples belong to the $\mathrm{H} 2$ and $\mathrm{H} 3$ types. Relationships among average pore diameter, Brunner-Emmet-Teller (BET) specific surface area, pore volume, porosity and permeability have been discussed. The heterogeneities of shale nanopore structures were verified, and nanopore size mainly concentrates under $30 \mathrm{~nm}$. The average fractal dimension $D_{1}$ of all the samples is 2.1187 , varying from 1.1755 to 2.6122 , and the average fractal dimension $\mathrm{D}_{2}$ is 2.4645 , with the range from 2.2144 to 2.7362. Compared with $D_{1}, D_{2}$ has stronger relationships with pore structure parameters, and can be used for analyzing pore structure characteristics.
\end{abstract}

Keywords: nanopore; pore structure; shale; tight sandstone; mudstone; nitrogen adsorption; fractal

\section{Introduction}

In recent years, global energy shortages have led to more attention being paid to unconventional oil and gas sources, such as tight oil and shale gas [1,2]. The pore-size of unconventional reservoir formations such as shale and tight sandstone generally spans from micropore to mesopore and macropore. In shale a very complicated pore structure is the result of a wide pore-size distribution and abundant organic matter [3]. Therefore, it is a huge challenge to explore unconventional resources effectively. The study of nanopore structure characteristics of unconventional reservoirs is important for their effective development, as nanopores can contain huge amounts of oil and gas.

There exist various techniques to investigate the characteristics of shale and tight sandstone and their respective nanopore structures, e.g., via mercury intrusion [4,5], field emission scanning electron microscopy, transmission electron microscopy (TEM), and gas adsorption analysis [6]. For example, Ghanbarian et al. analyzed 18 tight-gas sandstones from Texas by mercury intrusion experiments, and the EMA model was used to estimate bulk electrical conductivity and permeability [7]. Low-pressure gas adsorption measurements are very important for characterization of the gas shale 
pore system. Based on scanning electron microscopy and nitrogen adsorption experiments, Chen et al. found that most of the pores in shale are composed of organic pores and the pores in clay mineral layers [8]. Millán et al. proposed a truncated version of the fractal Frenkel-Halsey-Hill (FHH) model for describing $\mathrm{H}_{2} \mathrm{O}$-vapor adsorption and $48 \mathrm{H}_{2} \mathrm{O}$-vapor adsorption isotherm data was used to verify the model [9]. Yang et al. conducted low-pressure nitrogen adsorption studies on eight core samples from upper Ordovician lower Silurian oil reservoirs in the south of Sichuan Basin to better understand the reservoir characteristics of organic-rich shale [10]. In addition, fractal theory has been used to evaluate the pore structure in porous media. Wang et al. compared six different fractal models for calculating the fractal dimensions from mercury intrusion capillary pressures, and an optimal fractal model for analyzing petrophysical properties was recommended [11]. Based on nitrogen adsorption experiments, Ming et al. found that the fractal dimensions of shale have a good positive correlation with total pore volume, micropore volume and mesopore volume, but a poor correlation with macropore volume [12]. Xiong et al. used the FHH model to calculate surface fractal dimensions and volume fractal dimensions from nitrogen adsorption data [13]. Shao et al. analyzed the pore throat structure and fractal characteristics of Longmaxi shale with a series of experiments, and found that shale pore structure is mainly determined by total organic carbon content and thermal maturity, which also affects the value of the fractal dimensions [14]. Li et al. used the FHH model to obtain the fractal dimensions of shale, and the relationships between the calculated fractal dimensions and shale composition and total organic matter content were studied [15]. In this paper, fractal theory was used to study the nanopore structure characteristics of shale, tight sandstone and mudstone from the Yanchang Formation in the Ordos Basin of China based on the nitrogen adsorption experiments. The relationships between the calculated fractal dimensions and pore structure parameters, such as pore diameter and pore volume, were investigated.

\section{Core samples and Experiment Results}

\subsection{Core samples}

A total of 14 core samples, including 10 shale core samples, three tight sandstone core samples and one mudstone core sample collected from the Ordos Basin of China were selected in this study.

All samples are taken from fresh cores of different underground depths. The parameters of the collected samples are summarized in Table 1.

Table 1. The information of collected samples in this study.

\begin{tabular}{cccc}
\hline Core No. & Top Depth & Bottom Depth & Lithology \\
\hline 2 & 2069.88 & 2070.00 & Shale \\
8 & 2070.77 & 2070.87 & Shale \\
10 & 2071.08 & 2071.25 & Shale \\
17 & 2071.98 & 2072.08 & Shale \\
26 & 2073.18 & 2073.30 & Shale \\
33 & 2074.19 & 2074.35 & Shale \\
14 & 2000.78 & 2000.94 & Silty mudstone \\
$53-54$ & 2005.19 & 2005.40 & Sandstone \\
42 & 2028.72 & 2029.00 & Fine sandstone \\
58 & 2049.93 & 2050.09 & Shale \\
24 & 2054.12 & 2054.33 & Sandstone \\
32 & 2073.93 & 2074.19 & Shale \\
$32-2$ & 2073.93 & 2074.19 & Shale \\
$58-2$ & 2049.93 & 2050.09 & Shale \\
\hline
\end{tabular}

\subsection{X-ray diffraction $(X R D)$ measurements}

$\mathrm{XRD}$ is an effective technique to analyze mineral composition and content. Its theoretical basis is that X-rays will diffract in different directions and the mineral composition and structure can be determined by measuring the intensities and angles of these diffracted X-ray beams. As shown 
in Table 2, the contents of each component in shale and tight sandstone are significantly different. Although the four samples are both rich in clay minerals and quartz, the clay content in shale is greater than in tight sandstone. The clay content for shale samples ranged from $24.8 \%$ to $35.0 \%$, while for tight sandstone the clay content varied from $13.3 \%$ to $19.8 \%$. The shale quartz content is between $23.3 \%$ and $37.2 \%$, and less than that in sandstone, which varies between $60.9 \%$ and $61.3 \%$. The content of potash feldspar in shale and sandstone is not that much, with contents between $0.5 \%-2.0 \%$ and $0.3 \%-1.4 \%$, respectively. Plagioclase feldspar contained in shale is not as abundant as in sandstone, which is about $6 \%$ more than shale. The shale also contains a large proportion of pyrite, and sample 32 even contains $42.5 \%$ pyrite, while no pyrite can be found in sandstone. In general, the total amount of clay minerals and non-clay minerals in shale and sandstone samples are significantly different.

Table 2. Mineralogical composition results and total clay.

\begin{tabular}{ccccccccc}
\hline \multirow{2}{*}{$\begin{array}{c}\text { Core } \\
\text { No. }\end{array}$} & \multirow{2}{*}{ Lithology } & \multirow{2}{*}{ Total } & \multicolumn{5}{c}{ Mineralogical Composition Results (\%) } \\
\cline { 3 - 8 } & & Clay (\%) & Quartz & Potash Feldspar & Plagioclase Feldspar & Calcite & Dolomite & Pyrite \\
\hline 24 & Sandstone & 19.8 & 60.9 & 1.4 & 11.5 & 1.7 & 4.7 & $/$ \\
32 & Shale & 24.8 & 23.3 & 2.0 & 4.7 & 1.6 & 1.1 & 42.5 \\
58 & Shale & 35.0 & 37.2 & 0.5 & 4.5 & $/$ & 13.5 & 9.3 \\
53 & Sandstone & 13.3 & 61.3 & 0.3 & 11.0 & 2.4 & 11.7 & $/$ \\
\hline
\end{tabular}

The relative contents of clay minerals of the four samples are given in Table 3. The samples do not contain $S$ and C/S, but I and I/S are the most abundant. The content of $I$ is $41 \%-80 \%$ in shale and $40 \%-46 \%$ in tight sandstone. In addition to sample 32 without I/S, the I/S of the other three samples is about $40 \%$. This sample also contains certain kaolinite and chlorite. The content of kaolinite in shale is higher than that in tight sandstone, but the content of chlorite in shale is less than that in tight sandstone. The mixed-layer ratio of I/S in the sandstone is about $10 \%$, but C/S mixed-layer is not found in tight sandstone and shale samples.

Table 3. Relative clay mineral contents and mixed-layer ratio.

\begin{tabular}{|c|c|c|c|c|c|c|c|c|c|}
\hline \multirow{2}{*}{$\begin{array}{c}\text { Sample } \\
\text { No. }\end{array}$} & \multirow{2}{*}{ Lithology } & \multicolumn{6}{|c|}{ Relative Clay Mineral Contents (\%) } & \multicolumn{2}{|c|}{ Mixed-Layer Ratio (\%) } \\
\hline & & $S$ & $\mathrm{I} / \mathrm{S}$ & I & K & $\mathrm{C}$ & $\mathrm{C} / \mathrm{S}$ & $\mathrm{I} / \mathrm{S}$ & $\mathrm{C} / \mathrm{S}$ \\
\hline 24 & Sandstone & / & 39 & 46 & / & 15 & / & 10 & / \\
\hline 32 & Shale & / & / & 80 & 20 & / & / & / & / \\
\hline 58 & Shale & I & 40 & 41 & 7 & 12 & / & 10 & I \\
\hline 53 & Sandstone & / & 34 & 40 & 6 & 20 & I & 10 & / \\
\hline
\end{tabular}

Note: S: smectite; I/S: illite smectite mixed layer; I: illite; K: kaolinite; C: chlorite; C/S: chlorite smectite mixed-layer.

\subsection{Low-Pressure Nitrogen Adsorption-Desorption Experiments}

Low-pressure nitrogen adsorption-desorption experiments were conducted using an automatic specific surface area \& pore size analyzer produced by Quantachrome Instruments (Boynton Beach, FL, USA). The shapes of the nitrogen adsorption-desorption isotherms can be used to analyze pore shapes. Also, nitrogen adsorption-desorption data can be used to calculate the pore structure parameters. For example, total pore volume can be calculated as the liquid molar volume of adsorbed nitrogen at the relative pressure of 0.99 . Total pore volume and pore size distribution can be calculated based on the Barrett-Joyner-Halenda (BJH) model [16]. The principle of nitrogen adsorption is that the gas adsorbed on a certain surface is taken as a function of the relative pressure of the adsorbent. Under the constant temperature, the relationship between gas adsorption and gas balance relative pressure is the adsorption isotherm.

Isothermal adsorption and desorption curves were obtained by nitrogen adsorption experiment with relative pressure $\mathrm{P} / \mathrm{P}_{0}$ as abscissa and adsorption amount as ordinate. The nitrogen adsorption curves of 10 shale samples and one mudstone sample are shown in Figure 1, while the nitrogen adsorption curves of three sandstone samples are given in Figure 2. 
Nitrogen adsorption-desorption curves can be used to characterize the characteristics of pore complexity and shape. Figures 1 and 2 show that the adsorption-desorption curves of each sample are slightly different in morphology, but the whole curve is inverted S-type. The adsorption process can be divided into three stages: The first stage $\left(0<\mathrm{P} / \mathrm{P}_{0} \leq 0.4\right)$ is the nitrogen adsorption of low pressure stage, where the gas adsorption quantity increases slowly, and the adsorption isotherm is a gentle upward convex shape. The first stage is the single-layer adsorption of nitrogen on the pore surface, and the nitrogen adsorption curve appeared inflection point for monolayer adsorption to the transition of multilayer adsorption [17]. In the second stage $\left(0.4<\mathrm{P} / \mathrm{P}_{0} \leq 0.9\right)$, the adsorption volume of the sample increases rapidly with the increase of relative pressure, and nitrogen adsorption isotherm rises rapidly, which leads to a hysteresis loop, and this stage is a multi-molecular layer stage. In the third stage $\left(\mathrm{P} / \mathrm{P}_{0}>0.9\right)$, with the increase of relative pressure, the amount of gas adsorption increases dramatically.
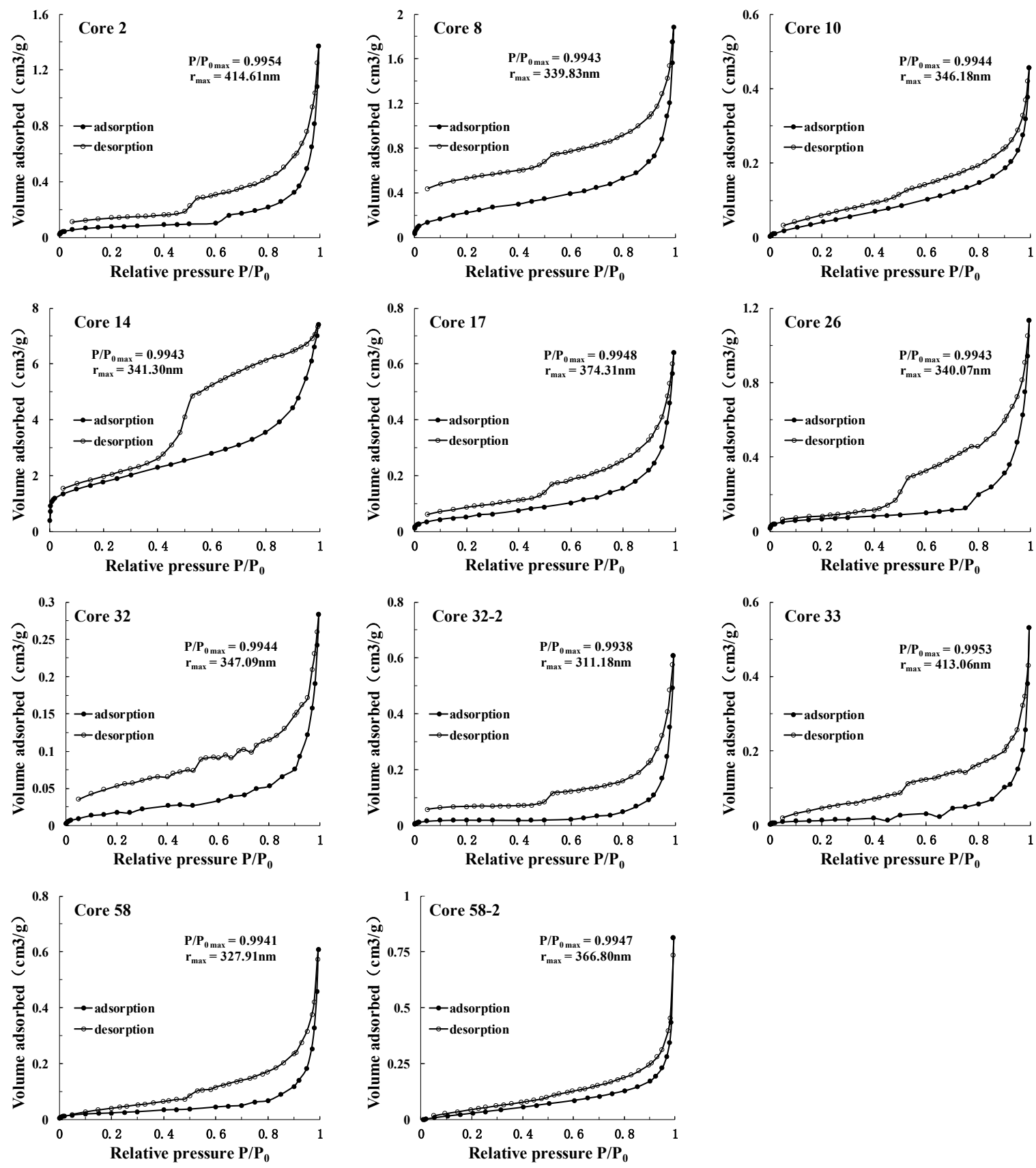

Figure 1. Nitrogen adsorption-desorption curve of samples of shale and mudstone. 

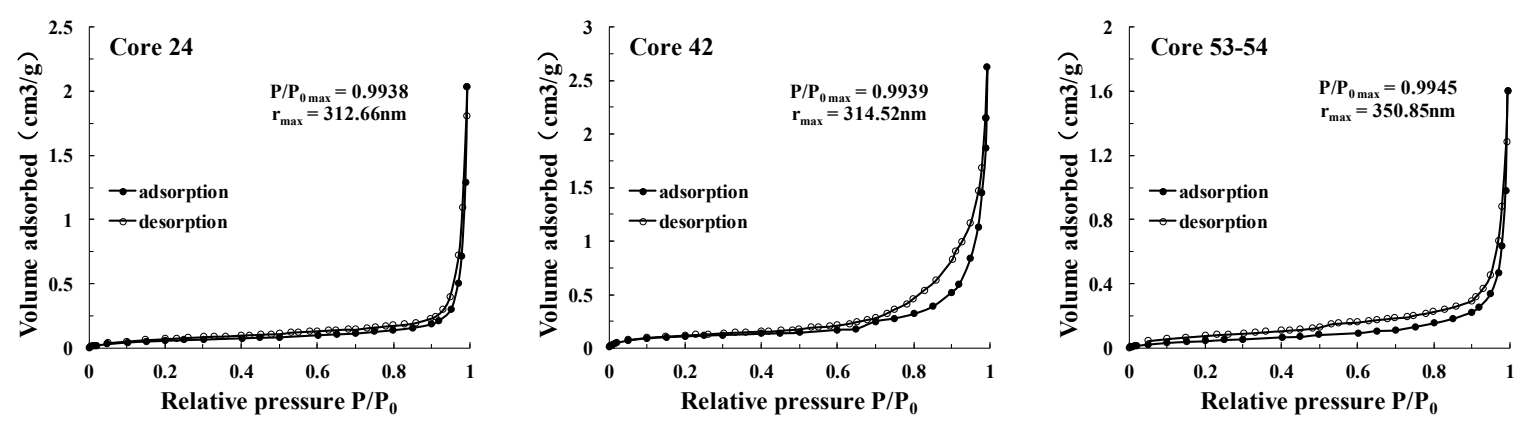

Figure 2. Nitrogen adsorption-desorption curve of three sandstone samples.

When the relative pressure was close to the saturated vapor pressure, there is no adsorption saturation phenomenon, and this is the capillary condensation stage of the sample. Due to the complex pore structure of the experimental samples, capillary condensation phenomena happen in the substrate surface, and the isothermal desorption curves of the samples show more obvious desorption hysteresis. The desorption amount is far less than the adsorption amount, and then hysteresis loop appeared. There are significant differences in the development morphology and connectivity of small pores and the adsorption of nitrogen is not fully enclosed [18].

According to IUPAC isotherm classification standard, the morphology of the nitrogen adsorption curves of the 10 shale samples and a mudstone one (sample 14) belong to the $\mathrm{H} 2$ and $\mathrm{H} 3$ type, indicating that the pore morphologies of shale are mainly similar to ink bottle holes and sheet granular matrix. As shown in Figure 2, the nitrogen adsorption curves of the sandstone samples are similar to $\mathrm{H} 3$ type, which indicates that the sandstone pores are mainly composed of sheet particles with non-rigid aggregate groove holes. As the pore openness is associated with increased rate of adsorption line, the larger the increasing rate is, the larger the opening of sandstone pore will be.

\section{Pore Size Distribution from Nitrogen Adsorption-Desorption Isotherms}

\subsection{Methods}

\subsubsection{Specific Surface Area}

The BET equation derived by Brunauer, Emmett and Teller was used to calculate the specific surface area with the range of relative pressure of $0.05-0.35$ [19]. The surface area of porous media can be calculated by the amount of gas monolayer adsorption according to the Langmuir monolayer adsorption theory:

$$
S_{B E T}=V_{m} N_{A} A_{m} / 22400 \mathrm{~W}
$$

where $N_{A}$ is Avogadro constant; $A_{m}$ is the cross section area of adsorbed gas nitrogen molecule; $W$ is the quality of the medium; $V_{m}$ is the nitrogen saturation adsorption amount in a single layer and can be calculated by the BET equation:

$$
\frac{1}{V\left(p_{0} / p-1\right)}=\frac{1}{V_{m} C}+\frac{C-1}{V_{m} C} \frac{p}{p_{0}}
$$

where $V$ is total volume of adsorbed gases and $C$ is a constant relating to adsorption.

\subsubsection{Pore Size}

The recurrence method is usually used to calculate the pore radius of different pore size intervals based on the Kelvin principle based on the assumption of cylindrical pore [20]. Assume the thickness of film adsorbed on the pore surface is $t$, and the internal radius of the pore with the radius $r_{p}$ is reduced to $r_{p}-t$, and can be calculated by [21]: 


$$
\ln \left(p / p_{0}\right)=\frac{-2 \gamma V_{m}}{R T\left(r_{p}-t\right)}
$$

where $\gamma$ is the surface tension at the boiling point of nitrogen; $V_{m}$ is the molar volume of liquid nitrogen; $R$ is the gas constant; $T$ is the boiling points $(77 \mathrm{~K}) ; p / p_{0}$ is the relative pressure of nitrogen. The thickness of the liquid film adsorbed on the pore surface can be calculated by [22]:

$$
t=\left[\frac{13.99}{0.034-\log \left(p / p_{0}\right)}\right]^{1 / 2}
$$

\subsubsection{Pore Size Distribution}

There are three different widely used methods for pore size distribution calculation based on gas adsorption isotherm, including the BJH method, HK method and DFT method $[23,24]$. The three method are introduced, respectively, and this paper uses the BJH model to calculate the pore size distribution.

Barrett et al. analyzed the desorption process and proposed the BJH method to calculation pore size distribution [16]. According to the desorption line of isothermal adsorption curve, the pore size distribution is obtained by calculating the nitrogen adsorption amount when the relative pressure is 0.99. The calculation formula is as follows:

$$
V_{p n}=\left(\frac{r_{p n}}{r_{k n}+\Delta t_{n}}\right)^{2}\left(\Delta V_{n}-\Delta t_{n} \sum_{j-1}^{n-1} A_{c j}\right)
$$

where $V_{p n}$ is the pore volume; $r_{p n}$ is the maximum pore radius; $r_{k n}$ is the capillary radius; $V_{n}$ is capillary volume; $t_{n}$ is the adsorbed nitrogen layer thickness; $A_{c j}$ is the area after the emptying.

Horváth et al. proposed the HK method to calculation pore size distribution [25]:

$$
w / w_{\infty}=f\left(l-d_{a}\right)
$$

where $w$ is the mass of nitrogen adsorbed on the pore surface; $w_{\infty}$ is the maximum amount of nitrogen adsorbed into the pores at $P / P_{0}=0.9 ; l$ is the distance between the nuclei of the two layers; $d_{a}$ is the diameter of adsorbent. According to the adsorption capacity of different pore sizes, the pore size distribution $f$ can be obtained by plotting the curve of $w / w_{\infty}$ versus $\left(l-d_{a}\right)$.

Seaton et al. [26] calculated the pore size distribution by the adsorption isotherm using the DFT method firstly. Pore size distribution can be obtained by solving the following equation:

$$
N_{\exp }\left(P / P_{0}\right)=\int_{D_{\min }}^{D_{\max }} N_{D F T}\left(P / P_{0}, D\right) f(D) d D
$$

where $N_{\exp }\left(P / P_{0}\right)$ is the experimental isotherm; $N_{D F T}\left(P / P_{0}, D\right)$ is the theoretical isotherm; $D$ is the pore size; $f(D)$ is the pore size distribution.

\subsection{Analysis of Experimental Results}

The calculated specific surface area, pore volume and pore size of shale, tight sandstone and mudstone are introduced respectively. Table 4 shows the calculation results for shale samples. It can be observed that BET specific surface area of the 10 shale samples is distributed between $0.05175 \mathrm{~m}^{2} / \mathrm{g}$ and $0.8988 \mathrm{~m}^{2} / \mathrm{g}$, with an average of $0.2345 \mathrm{~m}^{2} / \mathrm{g}$. The pore volume of BJH is distributed between $4.359 \times 10^{-4} \mathrm{cc} / \mathrm{g}$ and $27.18 \times 10^{-4} \mathrm{cc} / \mathrm{g}$, with an average of $12.7 \times 10^{-4} \mathrm{cc} / \mathrm{g}$. The weighted average pore diameter is between $12.72 \mathrm{~nm}$ and $63.8 \mathrm{~nm}$, with an average of $30.9 \mathrm{~nm}$. Shale has the characteristics of small pore size and large BET specific surface area, which is similar to the results presented in Literature [19]. 
Table 4. The calculated specific surface area, pore volume and pore size of shale samples.

\begin{tabular}{|c|c|c|c|c|c|c|c|c|c|}
\hline \multirow{2}{*}{$\begin{array}{l}\text { Core } \\
\text { No. }\end{array}$} & \multicolumn{3}{|c|}{ Specific Surface Area $\left(10^{-2} \mathrm{~m}^{2} / \mathrm{g}\right)$} & \multicolumn{3}{|c|}{ Pore Volume $\left(10^{-4} \mathrm{cc} / \mathrm{g}\right)$} & \multicolumn{3}{|c|}{ Pore Diameter (nm) } \\
\hline & BET & BJH & DFT & BJH & DFT & $\begin{array}{l}\text { Langmuir } \\
\text { Volume }\end{array}$ & $\begin{array}{l}\text { Weighted Average } \\
\text { Pore Diameter }\end{array}$ & BJH & DFT \\
\hline 2 & 28.30 & 28.60 & 27.67 & 21.58 & 14.21 & 1371.6 & 30.06 & 5.625 & 6.556 \\
\hline 8 & 89.88 & 49.88 & 67.31 & 27.18 & 21.06 & 1886.5 & 13.02 & 3.414 & 4.887 \\
\hline 10 & 22.22 & 16.08 & 16.45 & 6.808 & 5.161 & 455.5 & 12.72 & 3.454 & 6.079 \\
\hline 17 & 20.22 & 17.31 & 18.84 & 9.686 & 7.641 & 640.7 & 19.66 & 3.414 & 6.079 \\
\hline 26 & 24.24 & 20.83 & 24.61 & 17.50 & 12.68 & 1134.3 & 29.03 & 9.592 & 9.098 \\
\hline 33 & 5.175 & 12.94 & 6.435 & 8.922 & 1.625 & 532.3 & 63.80 & 3.834 & 9.416 \\
\hline 58 & 8.572 & 8.76 & 9.775 & 9.419 & 5.909 & 608.9 & 44.06 & 7.816 & 10.49 \\
\hline 32 & 7.474 & 6.30 & 6.827 & 4.359 & 3.284 & 283.9 & 23.56 & 5.638 & 7.310 \\
\hline $32-2$ & 8.011 & 8.48 & 8.551 & 9.686 & 6.135 & 609.5 & 47.19 & 6.543 & 11.68 \\
\hline $58-2$ & 20.36 & 16.34 & 14.68 & 12.61 & 6.218 & 813 & 24.76 & 3.451 & 6.079 \\
\hline Average & 23.45 & 18. 55 & 20.11 & 12.7 & 8.39 & 833.62 & 30.9 & 5.28 & 7.77 \\
\hline
\end{tabular}

The pore structure parameters of the three tight sandstone samples obtained from the nitrogen adsorption-desorption isotherms are listed in Table 5.

Table 5. The calculated specific surface area, pore volume and pore size of tight sandstone samples.

\begin{tabular}{|c|c|c|c|c|c|c|c|c|c|}
\hline \multirow{2}{*}{$\begin{array}{c}\text { Core } \\
\text { No. }\end{array}$} & \multicolumn{3}{|c|}{ Specific Surface Area $\left(10^{-2} \mathrm{~m}^{2} / \mathrm{g}\right)$} & \multicolumn{3}{|c|}{ Pore Volume $\left(10^{-4} \mathrm{cc} / \mathrm{g}\right)$} & \multicolumn{3}{|c|}{ Pore Diameter (nm) } \\
\hline & BET & BJH & DFT & BJH & DFT & $\begin{array}{l}\text { Langmuir } \\
\text { Volume }\end{array}$ & $\begin{array}{c}\text { Average Pore } \\
\text { Diameter }\end{array}$ & BJH & DFT \\
\hline 24 & 23.70 & 17.23 & 23.54 & 31.25 & 15.36 & 2029.4 & 53.20 & 4.644 & 29.40 \\
\hline 42 & 40.90 & 42.24 & 61.23 & 41.14 & 24.67 & 2624.1 & 39.79 & 6.547 & 12.55 \\
\hline $53-54$ & 18.60 & 20.17 & 30.10 & 24.84 & 12.04 & 1596.6 & 53.12 & 3.826 & 8.145 \\
\hline Average & 27.73 & 26.55 & 38.29 & 32.41 & 17.36 & 2083.37 & 48.70 & 5.01 & 16.70 \\
\hline
\end{tabular}

It is shown that the BET specific surface area of the three sandstone samples is distributed between $0.1864 \mathrm{~m}^{2} / \mathrm{g}$ and $0.4091 \mathrm{~m}^{2} / \mathrm{g}$, with an average of $0.2231 \mathrm{~m}^{2} / \mathrm{g}$. The pore volume of BJH is distributed between $0.002484 \mathrm{cc} / \mathrm{g}$ and $0.004114 \mathrm{cc} / \mathrm{g}$, with an average of $0.003241 \mathrm{cc} / \mathrm{g}$. The average pore diameter ranges from $39.79 \mathrm{~nm}$ to $53.20 \mathrm{~nm}$, and the average pore diameter is $48.70 \mathrm{~nm}$. Compared with shale, BET specific surface area of the sandstone sample is smaller than that of the shale, and the pore volume and the average pore diameter are larger than those of the shale.

The experimental data of the silty mudstone sample is shown in Table 6. The BET specific surface area of the mudstone sample is $6.33 \mathrm{~m}^{2} / \mathrm{g}$, the $\mathrm{BJH}$ pore volume is $93.46 \times 10^{-4} \mathrm{cc} / \mathrm{g}$, and the average pore diameter is $7.272 \mathrm{~nm}$. Compared with the shale and sandstone samples, the BET specific surface area of the mudstone sample is much larger, and the pore volume and average pore diameter are much smaller.

Table 6. The calculated specific surface area, pore volume and pore size of mudstone sample.

\begin{tabular}{cccccccccc}
\hline $\begin{array}{c}\text { Core } \\
\text { No. }\end{array}$ & \multicolumn{2}{c}{ Specific Surface Area $\left(\mathrm{m}^{2} / \mathrm{g}\right)$} & \multicolumn{2}{c}{ Pore Volume } & $\left(\mathbf{1 0}^{-4} \mathrm{cc} / \mathrm{g}\right)$ & \multicolumn{2}{c}{ Pore Diameter $(\mathrm{nm})$} & \\
\cline { 2 - 11 } & BET & BJH & DFT & BJH & DFT & $\begin{array}{c}\text { Langmuir } \\
\text { Volume }\end{array}$ & $\begin{array}{c}\text { Average Pore } \\
\text { Diameter }\end{array}$ & BJH & DFT \\
\hline 14 & 6.33 & 2.689 & 5.738 & 93.46 & 103 & 7421.1 & 7.272 & 3.819 & 3.78 \\
\hline
\end{tabular}

The pore size distributions of the 10 shales, one mudstone and three sandstones obtained from the BJH method are shown in Figures 3-5, respectively. The abscissa value of the peak was marked in the figures. As Figure 3 shows, the pore size distribution of shale has a certain heterogeneity, and mainly concentrated under $30 \mathrm{~nm}$, with at least one obvious peak value distributed in the range of about 3-10 nm. Figure 4 shows that the pore size distribution of mudstone sample has only one peak value which is not obvious, and the pore distribution is relatively uniform, and the pore diameter are mainly below $30 \mathrm{~nm}$. As shown in Figure 5, the pore distribution of the three sandstone samples 
mostly had two peaks from $3 \mathrm{~nm}$ to $10 \mathrm{~nm}$, which was similar to shale. The peak value of No. 24 is around $50 \mathrm{~nm}$. Compared with shale and mudstone, the heterogeneities of tight sandstone pore are relatively large, which also indicated that large and medium pores were the main contributors to gas storage space.
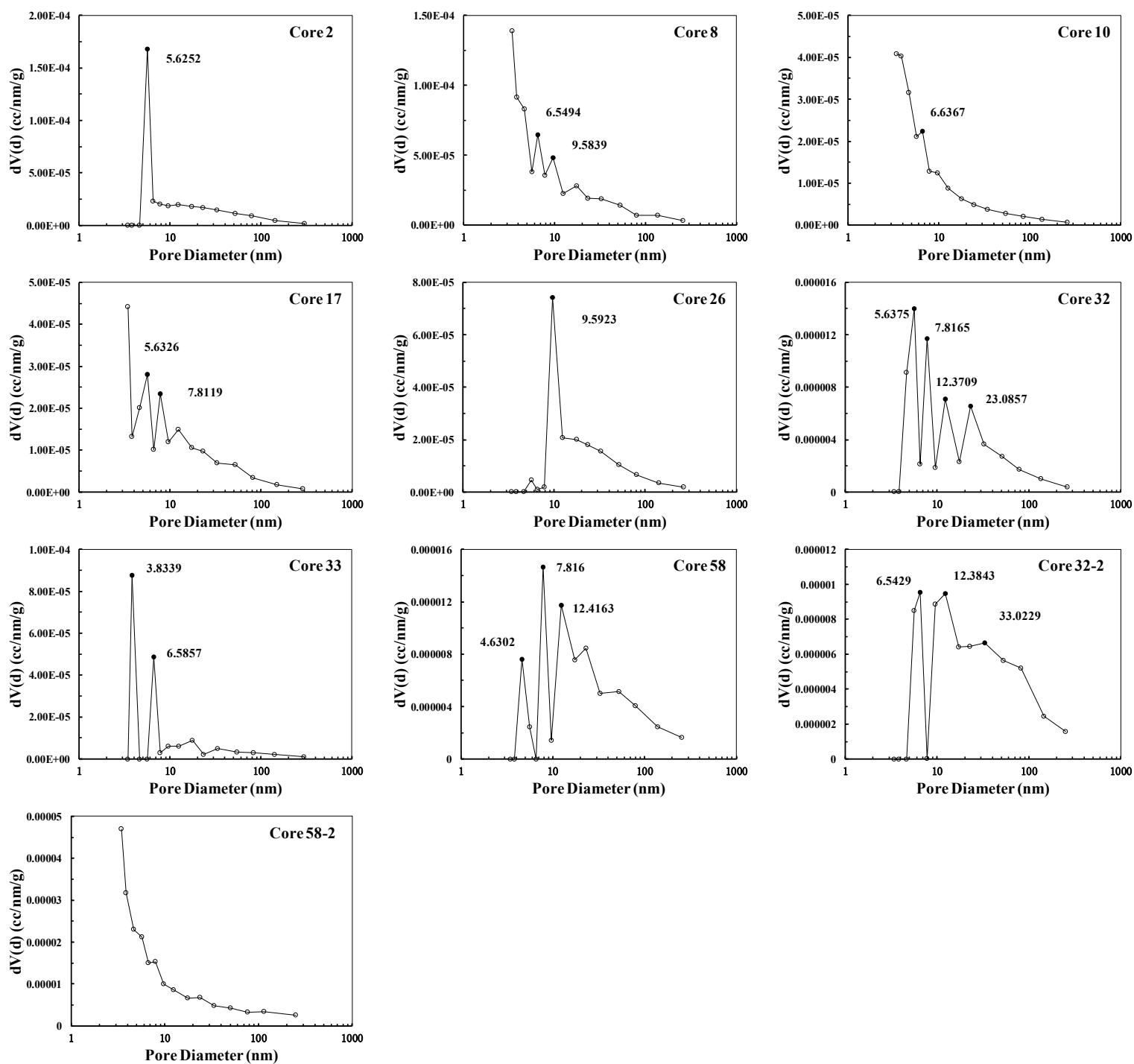

Figure 3. The pore size distribution of shale calculated by BJH method (The peak values of pore size distribution are marked by black circles, and the corresponding pore sizes are displayed).

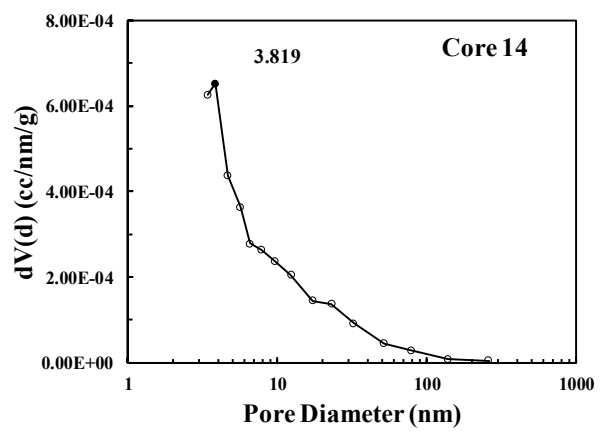

Figure 4. The pore size distribution of mudstone calculated by BJH method (The peak values of pore size distribution are marked by black circles, and the corresponding pore sizes are displayed). 

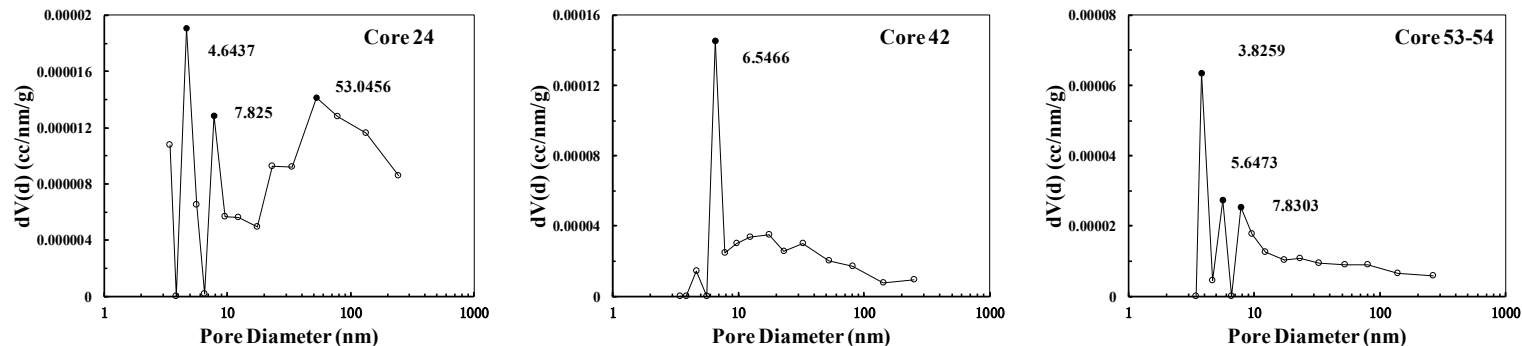

Figure 5. The pore size distribution of sandstone calculated by BJH method (the peak values of pore size distribution are marked by black circles, and the corresponding pore sizes are displayed).

\subsection{Pore parameter Relationships}

The relationship between average pore diameter and pore volume of the 10 shale samples is shown in Figure 6. It shows that there was no significant correlation between average pore diameter and pore volume of shale. As shown in Figure 7, the BET specific surface area of shale sample is negatively correlated with the average pore diameter, indicating that with the increase of average pore size, shale pore heterogeneity as well as the roughness decreases, and the specific surface area decreases. The relationship between shale pore volume and BET specific surface area is shown in Figure 8 . The specific surface area increases with increasing total pore volume, and the correlation coefficient is nearly 0.7 .

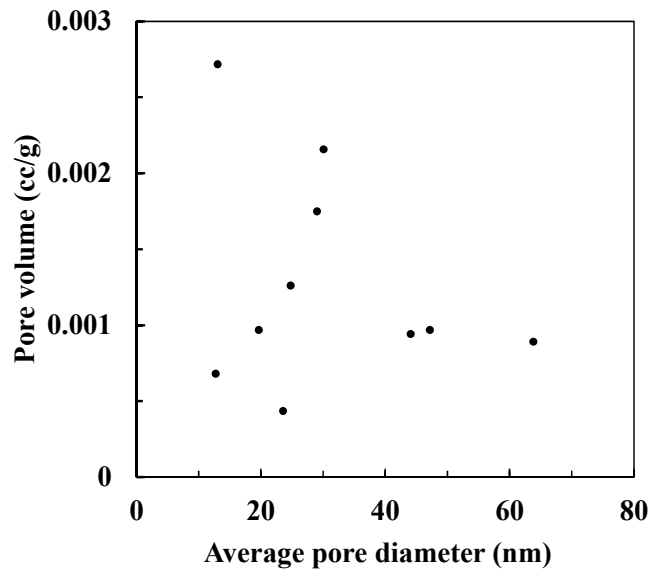

Figure 6. Relationship between average pore diameter and pore volume of shale samples.

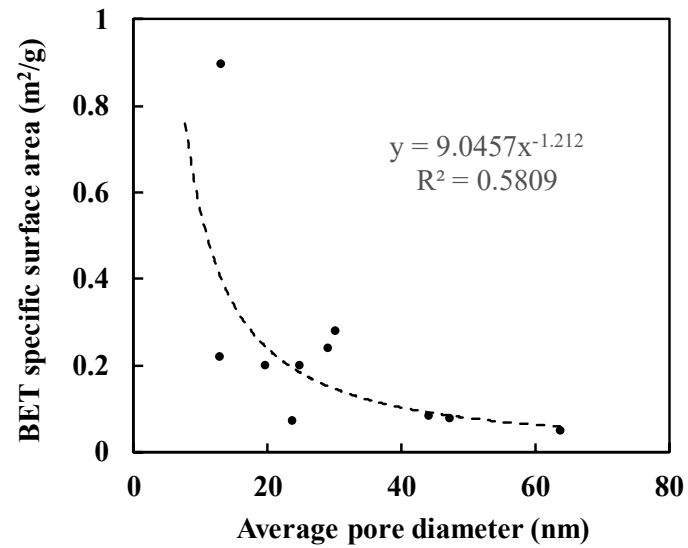

Figure 7. Relationship between average pore diameter and BET specific surface area of shale samples.

Porosity and permeability of four core samples including three tight sandstone samples and one mudstone sample were measured, as shown in Table 7 . The porosity and permeability of the 
mudstone sample are ultra-low. The permeability of mudstone is one order of magnitude smaller that of tight sandstone, and the porosity of mudstone is only slightly greater than $1 \%$. Figure 9 shows BET specific surface area decreases with the increase of permeability. The reason is that the larger the permeability is, the larger the corresponding average pore size will be, and it can be verified with Figure 10, which shows that the average pore size is positively correlated to the gas permeability.

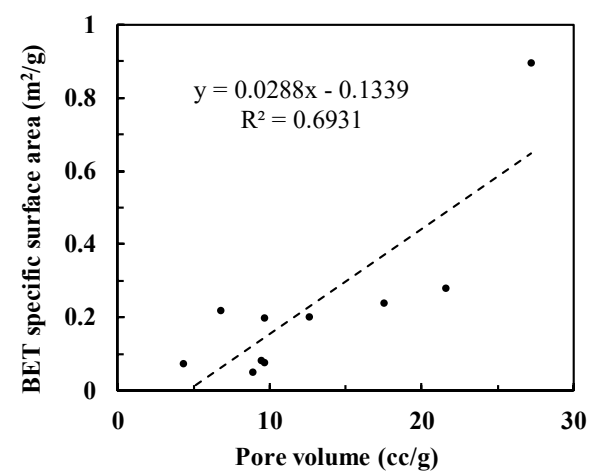

Figure 8. Relationship between pore volume and BET specific surface area of shale samples.

Table 7. Summary of pore parameters of 3 sandstone samples and 1 mudstone sample.

\begin{tabular}{|c|c|c|c|c|c|c|}
\hline $\begin{array}{l}\text { Core } \\
\text { No. }\end{array}$ & Lithology & $\begin{array}{l}\text { Porosity } \\
\text { (\%) }\end{array}$ & $\begin{array}{l}\text { Permeability } \\
\text { (mD) }\end{array}$ & $\begin{array}{c}\text { BET Specific Surface } \\
\text { Area }\left(\mathrm{m}^{2} / \mathrm{g}\right)\end{array}$ & $\begin{array}{l}\text { Average Pore } \\
\text { Diameter (nm) }\end{array}$ & $\begin{array}{l}\text { Pore Volume } \\
\left(10^{-3} \mathrm{cc} / \mathrm{g}\right)\end{array}$ \\
\hline $53-54$ & Tight sandstone & 8.07 & 0.09 & 0.1864 & 53.12 & 2.48 \\
\hline 42 & Tight sandstone & 6.49 & 0.027 & 0.4091 & 39.79 & 4.11 \\
\hline 24 & Tight sandstone & 8.07 & 0.056 & 0.2366 & 53.20 & 3.13 \\
\hline 14 & Mudstone & 1.05 & 0.0053 & 6.330 & 72.72 & 9.35 \\
\hline
\end{tabular}

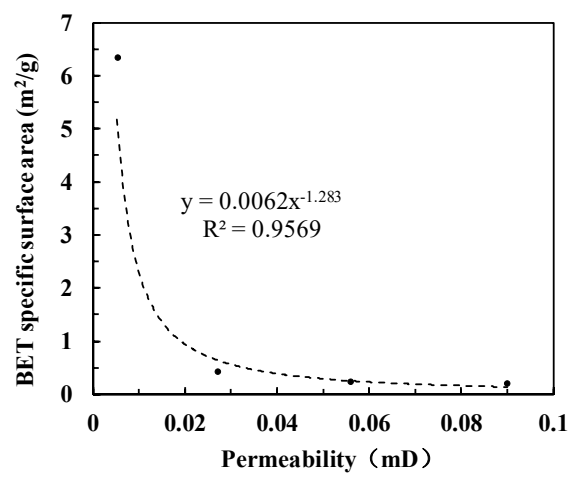

Figure 9. The relationship between gas permeability and specific surface area of 3 tight sandstone samples and 1 mudstone sample.

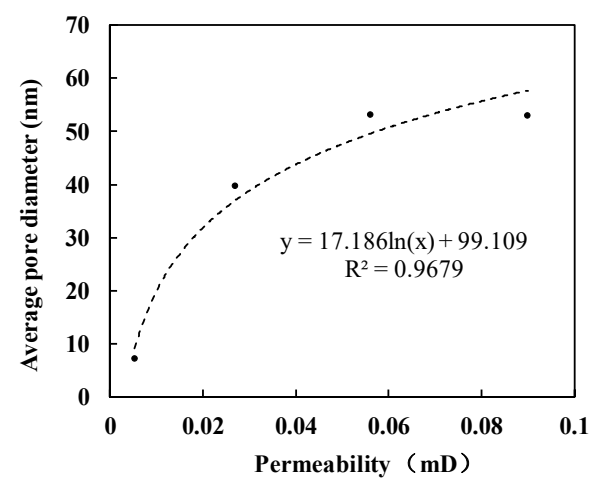

Figure 10. The relationship between gas permeability and average pore diameter of 3 tight sandstone samples and 1 mudstone sample. 


\section{Fractal Analysis of Nitrogen Adsorption Isotherms}

\subsection{Principle and Fractal Dimension Calculation Process}

Fractal theory has been widely used to characterize the pore structures of unconventional reservoirs [27-30]. Fractal dimensions can quantitatively evaluate the heterogeneity of pore structure, and generally, pore heterogeneity increases with the increasing fractal dimension [31]. There are many models for calculating fractal dimension from nitrogen adsorption isotherms, including BET model, FHH model, fractal Langmuir model and thermodynamic method, and the FHH model is the one widely applied [32]. According to the FHH model, the fractal dimension D can be calculated from nitrogen adsorption experiments with the following equation:

$$
\operatorname{Ln} V=K \operatorname{Ln}\left[\operatorname{Ln}\left(P_{0} / P\right)\right]+C
$$

where $P$ is the equilibrium pressure; $V$ is the volume of adsorbed gas corresponding to equilibrium pressure $P ; P_{0}$ is the saturation pressure, $K$ is the slope of the logarithmic curve, which is related to the adsorption mechanism and $K=\mathrm{D}-3 ; C$ is a constant. If the pores has fractal characteristics, $\ln V$ and $\ln \left(\ln \left(\mathrm{P}_{0} / \mathrm{P}\right)\right)$ will have a linear relationship [18].

The fractal dimension processes of the 10 shale samples are shown in Figure 11. The adsorption and desorption curves of the experimental samples produce hysteresis loops when relative pressure is about 0.4 , indicating that there is a large difference in porosity before and after this relative pressure due to different adsorption behaviors. There are two fractal characteristics in the study area. In this paper, the fractal dimension calculated from the low relative pressure range of $0<\mathrm{P} / \mathrm{P}_{0}<0.4$ is denoted as $\mathrm{D}_{1}$, and the fractal dimension calculated from the high relative pressure range of $0.4<\mathrm{P} / \mathrm{P}_{0}<1$ is denoted as $D_{2}$. The fractal dimension $D_{1}$ characterizes the effect of van der Waals force and reflects the surface roughness. The fractal dimension $\mathrm{D}_{2}$ represents properties of multi-layer adsorption, which can be used to describe the spatial roughness and irregularity of pore structures [33,34]. Ghanbarian and Daigle found that the cut-off values of the upper and lower boundaries of fractal regions have a significant impact on the results of fractal dimension calculation [35]. Meanwhile, when the curve is segmented, the boundaries of relative pressure is not constant at 0.4. In order to ensure the accuracy of fractal dimension calculation, this paper divides the curve according to the change of slope. The segmentation points of the curve are shown in Table 8.

Table 8. The upper and lower boundaries of relative pressure for fractal dimension calculation.

\begin{tabular}{cccc}
\hline \multirow{2}{*}{ Core No. } & \multicolumn{3}{c}{ Upper and Lower Boundaries of Relative Pressure for Each Fractal Regime } \\
\cline { 2 - 4 } & Initial Point & Segmentation Point & Ending Point \\
\hline 2 & 0.0099 & 0.4990 & 0.9954 \\
8 & 0.0096 & 0.3001 & 0.9896 \\
10 & 0.0101 & 0.4035 & 0.9944 \\
17 & 0.0100 & 0.4004 & 0.9948 \\
26 & 0.0099 & 0.4493 & 0.9943 \\
33 & 0.0098 & 0.3990 & 0.9953 \\
14 & 0.0098 & 0.4003 & 0.9943 \\
24 & 0.0099 & 0.3010 & 0.9938 \\
32 & 0.0098 & 0.2995 & 0.9944 \\
$32-2$ & 0.0095 & 0.3998 & 0.9938 \\
42 & 0.0098 & 0.4011 & 0.9888 \\
$53-54$ & 0.0096 & 0.4016 & 0.9945 \\
58 & 0.0097 & 0.2999 & 0.9941 \\
$58-2$ & 0.0545 & 0.3146 & 0.9947 \\
\hline
\end{tabular}

In Figure 11, the curves for calculating fractal dimension $\mathrm{D}_{1}$ and $\mathrm{D}_{2}$ are displayed. For the core 2 , core 26 and core 33, the slopes of the two curves before and after the segmentation points are close 
to each other can be fitted by a straight line. The reason is that the pore radii of these cores are small and their distributions are concentrated, which leads to that their surface fractal dimensions are close to the volume fractal dimension. For the core $32-2$, the curve of $D_{2}$ calculation is not linear and the linear correlation is very poor. Therefore, the fractal dimension $\mathrm{D}_{2}$ of core 32-2 was not calculated. The values of $D_{1}$ and $D_{2}$ are shown in Table 9. $D_{1}$ is distributed between 1.67 and 2.5265 with an average value of $2.1975, \mathrm{D}_{2}$ is distributed between 2.3076-2.6463 with an average value of 2.4791 .
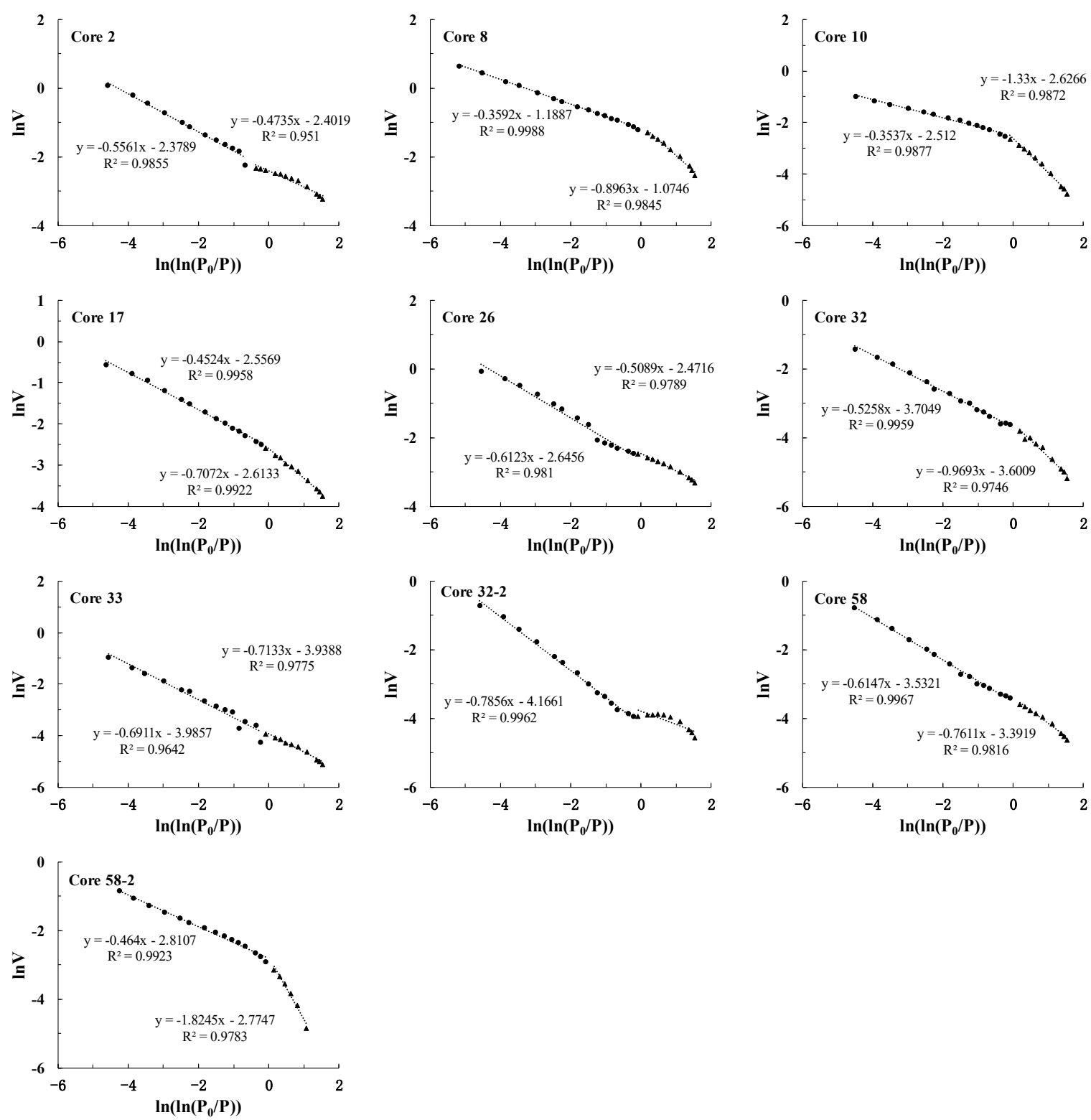

Figure 11. The curves of fractal dimension calculation for 10 shale samples.

The curves of fractal dimension calculation for the three tight sandstone samples and one mudstone sample are shown in Figures 12 and 13, respectively, and the calculated fractal dimensions $D_{1}$ and $D_{2}$ are shown in Tables 10 and 11, respectively. 
Table 9. The calculated fractal dimensions of 10 shale samples.

\begin{tabular}{ccccccc}
\hline \multirow{2}{*}{ Core No. } & \multicolumn{3}{c}{$\mathbf{0}<\mathbf{P} / \mathbf{P}_{\mathbf{0}}<\mathbf{0 . 4}$} & \multicolumn{3}{c}{$\mathbf{0 . 4}<\mathbf{P} / \mathbf{P}_{\mathbf{0}}<\mathbf{1}$} \\
\cline { 2 - 6 } & $\mathbf{K}_{\mathbf{1}}$ & $\mathbf{D}_{\mathbf{1}}=\mathbf{3}+\mathbf{k}_{\mathbf{1}}$ & $\mathbf{R}^{\mathbf{2}}$ & $\mathbf{K}_{\mathbf{2}}$ & $\mathbf{D}_{\mathbf{2}}=\mathbf{3}+\mathbf{K}_{\mathbf{2}}$ & $\mathbf{R}^{\mathbf{2}}$ \\
\hline 2 & -0.4735 & 2.5265 & 0.951 & -0.5561 & 2.4439 & 0.9855 \\
8 & -0.8963 & 2.1037 & 0.9845 & -0.3592 & 2.6408 & 0.9988 \\
10 & -1.33 & 1.67 & 0.9872 & -0.3537 & 2.6463 & 0.9877 \\
17 & -0.7072 & 2.2928 & 0.9922 & -0.4524 & 2.5476 & 0.9958 \\
26 & -0.5364 & 2.4636 & 0.982 & -0.6123 & 2.3877 & 0.981 \\
33 & -0.7461 & 2.2539 & 0.9775 & -0.6924 & 2.3076 & 0.9684 \\
58 & -0.7611 & 2.2389 & 0.9816 & -0.6147 & 2.3853 & 0.9967 \\
32 & -0.9693 & 2.0307 & 0.9746 & - & - & - \\
$32-2$ & -0.3878 & 2.6122 & 0.7652 & -0.7856 & 2.2144 & 0.9962 \\
$58-2$ & -1.8245 & 1.1755 & 0.9783 & -0.464 & 2.536 & 0.9923 \\
Average & -0.8632 & 2.1368 & 0.9574 & -0.5416 & 2.4584 & 0.9898 \\
\hline
\end{tabular}
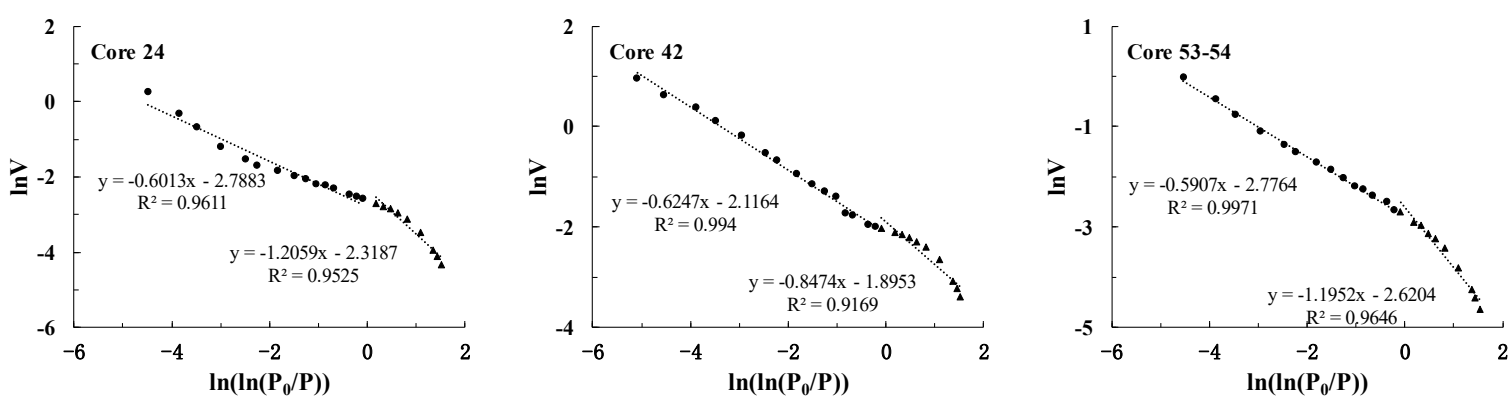

Figure 12. The curves of fractal dimension calculation for 3 tight sandstone samples.

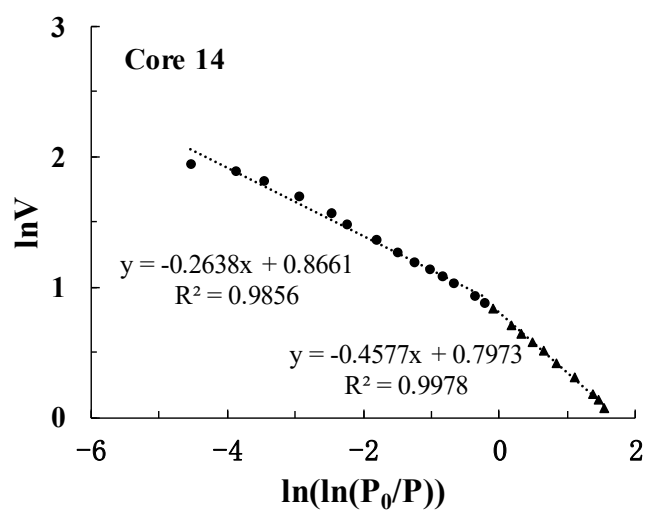

Figure 13. The curves of fractal dimension calculation for 1 mudstone sample.

Table 10. The calculated fractal dimensions of three tight sandstone samples.

\begin{tabular}{ccccccc}
\hline \multirow{2}{*}{ Core No. } & \multicolumn{3}{c}{$\mathbf{0}<\mathbf{P} / \mathbf{P}_{\mathbf{0}}<\mathbf{0 . 4}$} \\
\cline { 2 - 6 } & $\mathbf{K}_{\mathbf{1}}$ & $\mathbf{D}_{\mathbf{1}}=\mathbf{3}+\mathbf{k}_{\mathbf{1}}$ & $\mathbf{R}^{\mathbf{2}}$ & $\mathbf{K}_{\mathbf{2}}$ & $\mathbf{D}_{\mathbf{2}}=\mathbf{3}+\mathbf{K}_{\mathbf{2}}$ & $\mathbf{R}^{\mathbf{2}}$ \\
\hline $53-54$ & -1.1952 & 1.8048 & 0.9646 & -0.5907 & 2.4093 & 0.9971 \\
42 & -0.8474 & 2.1526 & 0.9169 & -0.6247 & 2.3753 & 0.994 \\
24 & -1.2059 & 1.7941 & 0.9525 & -0.6013 & 2.3987 & 0.9611 \\
Average & -1.0828 & 1.9172 & 0.9447 & -0.6056 & 2.3944 & 0.9841 \\
\hline
\end{tabular}

Table 11. The calculated fractal dimensions of one mudstone sample.

\begin{tabular}{ccccccc}
\hline \multirow{2}{*}{ Core No. } & \multicolumn{3}{c}{$\mathbf{0} \mathbf{P} / \mathbf{P}_{\mathbf{0}}<\mathbf{0 . 4}$} \\
\cline { 2 - 7 } & $\mathbf{K}_{\mathbf{1}}$ & $\mathbf{D}_{\mathbf{1}}=\mathbf{3}+\mathbf{k}_{\mathbf{1}}$ & $\mathbf{R}^{\mathbf{2}}$ & $\mathbf{K}_{\mathbf{2}}$ & $\mathbf{D}_{\mathbf{2}}=\mathbf{3}+\mathbf{K}_{\mathbf{2}}$ & $\mathbf{R}^{\mathbf{2}}$ \\
\hline 14 & -0.4577 & 2.5423 & 0.9978 & -0.2638 & 2.7362 & 0.9856 \\
\hline
\end{tabular}


For the tight sandstone samples, the calculated $\mathrm{D}_{1}$ changes from 1.7941 to 2.1526 with an average value of 1.9172 , and $\mathrm{D}_{2}$ varies from 2.3753 to 2.4093 with an average value of 2.3944 . The correlation coefficient $R^{2}$ is close to 1 , indicating that the pores in tight sandstone has good fractal characteristics. For the mudstone sample, the calculated $D_{1}$ is 2.5423 and the calculated $D_{2}$ is 2.7362 . It can be found that the values of $D_{1}$ and $D_{2}$ of mudstone are largest, followed by shale, and the values of $D_{1}$ and $D_{2}$ of tight sandstone are smallest.

As shown in Tables 9-11, it can be found that the surface fractal dimension $D_{1}$ is generally less than the volume fractal dimension $D_{2}$. The relationship between the fractal dimension $D_{1}$ and $D_{2}$ for shale samples is shown in Figure 14. The fractal dimension $\mathrm{D}_{2}$ decreases with the fractal dimension $\mathrm{D}_{1}$ increasing. The surface fractal dimensions $\mathrm{D}_{1}$ of the cores 10, 24,53-54, 58-2 are less than 2 which are not in the typical range: $2<\mathrm{D}<3$ for three-dimensional space. Ghanbarian-Alavijeh et al. believed that the fractal dimension can be $-\infty$ when the pore size is the same, and demonstrated that theoretically fractal dimension can range between $-\infty$ and 3 [36]. Therefore, the fractal dimension $D_{1}$ less than 2 is acceptable.

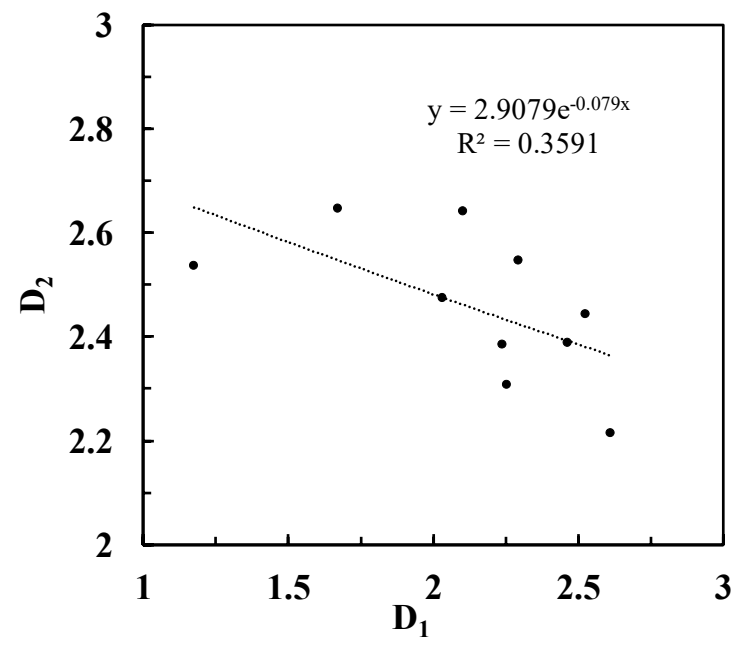

Figure 14. Relationship between the fractal dimension $D_{1}$ and $D_{2}$ of shale samples.

\subsection{Relationship between Fractal Dimensions and Pore Structure Parameters}

A summary of fractal dimensions and pore parameters of shale, sandstone and mudstone samples as shown in Table 12. The relationships between the calculated fractal dimensions and pore structure parameters will be studied below.

Table 12. Summary of fractal dimensions and pore parameters of shale, sandstone and mudstone.

\begin{tabular}{|c|c|c|c|c|c|c|c|}
\hline $\begin{array}{l}\text { Core } \\
\text { No. }\end{array}$ & $\mathrm{D}_{1}$ & $\mathbf{D}_{2}$ & $\begin{array}{l}\text { Specific Surface Area } \\
\qquad\left(\mathrm{m}^{2} / \mathrm{g}\right)\end{array}$ & $\begin{array}{l}\text { Average Pore Diameter } \\
\text { (nm) }\end{array}$ & $\begin{array}{l}\text { Porosity } \\
(\%)\end{array}$ & $\begin{array}{l}\text { Langmuir Volume } \\
\left(10^{-4} \mathrm{cc} / \mathrm{g}\right)\end{array}$ & $\begin{array}{l}\text { Permeability } \\
\text { (mD) }\end{array}$ \\
\hline 2 & 2.5265 & 2.4439 & 0.283 & 30.06 & - & 1371.6 & - \\
\hline 8 & 2.1037 & 2.6408 & 0.8988 & 13.02 & - & 1886.5 & - \\
\hline 17 & 2.2928 & 2.5476 & 0.2022 & 19.66 & - & 640.7 & - \\
\hline 26 & 2.4636 & 2.3877 & 0.2424 & 29.03 & - & 1134.3 & - \\
\hline 33 & 2.2539 & 2.3076 & 0.05175 & 63.8 & - & 532.3 & - \\
\hline $32-2$ & 2.6122 & 2.2144 & 0.08011 & 47.19 & - & 609.5 & - \\
\hline $58-2$ & 1.1755 & 2.536 & 0.2036 & 24.76 & - & 813 & - \\
\hline $53-54$ & 1.8048 & 2.4093 & 0.1864 & 53.12 & 8.07 & 1596.6 & 0.09 \\
\hline 42 & 2.1526 & 2.3753 & 0.4091 & 39.79 & 6.49 & 2624.1 & 0.027 \\
\hline 24 & 1.7941 & 2.3987 & 0.2366 & 53.2 & 9.8 & 2029.4 & 0.056 \\
\hline 14 & 2.5423 & 2.7362 & 6.33 & 7.272 & 1.05 & 7421.1 & 0.0053 \\
\hline
\end{tabular}




\subsubsection{Relationship between Fractal Dimension and Specific Surface area}

The relationship between specific surface area and fractal dimension of 10 shale samples and three sandstone samples is shown in Figure 15. There is no obvious relationship between $D_{1}$ and BET specific surface area, but BET specific surface area is positively correlated with $\mathrm{D}_{2}$, indicating that the larger the specific surface area is, the more complex pore structure will become.

\subsubsection{Relationship between Fractal Dimension and Average Pore Diameter}

As shown in Figure 16, average pore diameter of all samples has no obvious relationship between $D_{1}$, but is negatively correlated with $D_{2}$. With average pore diameter increasing, fractal dimension $D_{2}$ decreases exponentially, indicating properties of core samples become better.
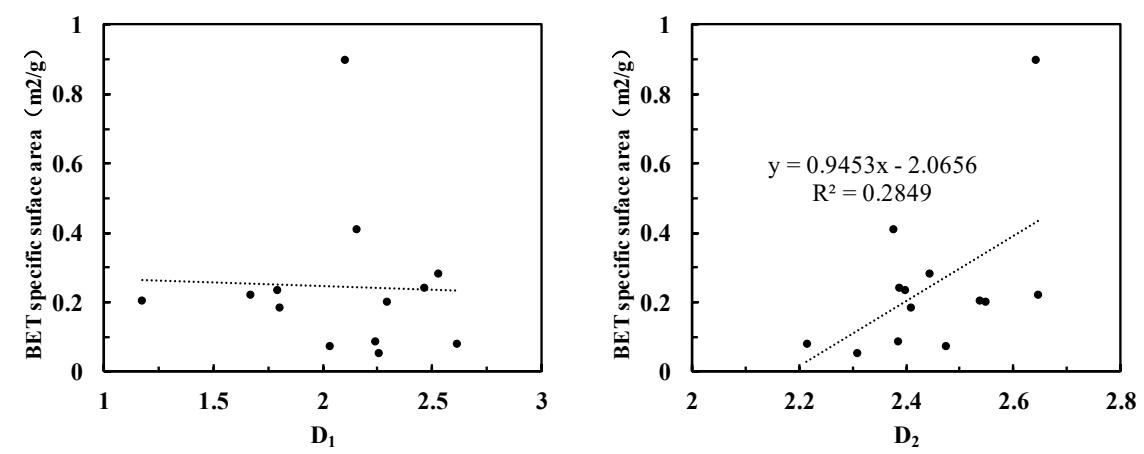

Figure 15. Relationship between fractal dimension and specific surface area.
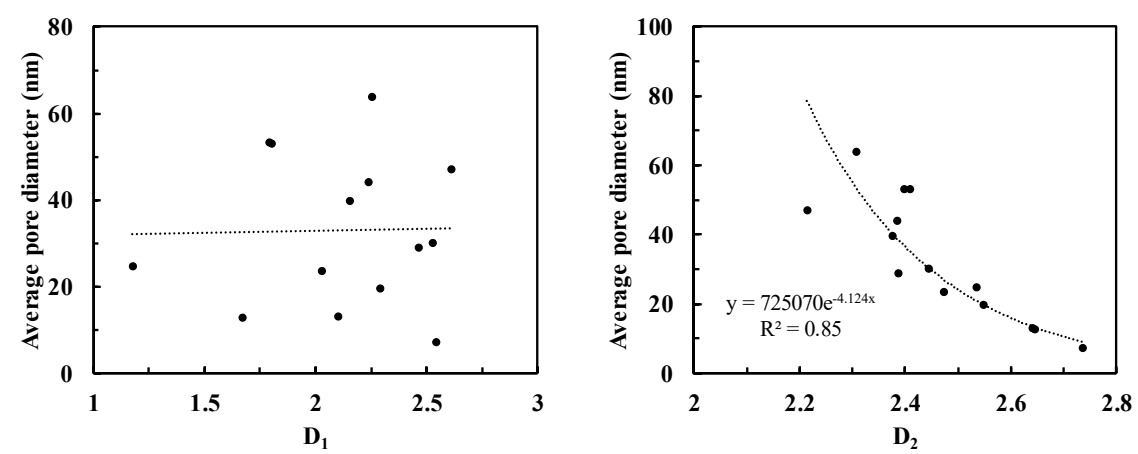

Figure 16. Relationship between fractal dimension and average pore diameter of all samples.

\subsubsection{Relationship between Fractal Dimension and Porosity}

As shown in Figure 17, the fractal dimension $\mathrm{D}_{1}$ and $\mathrm{D}_{2}$ of the three sandstone samples (Nos. 53-54, $42,24)$ and one mudstone sample (No. 14) are negatively correlated with porosity.
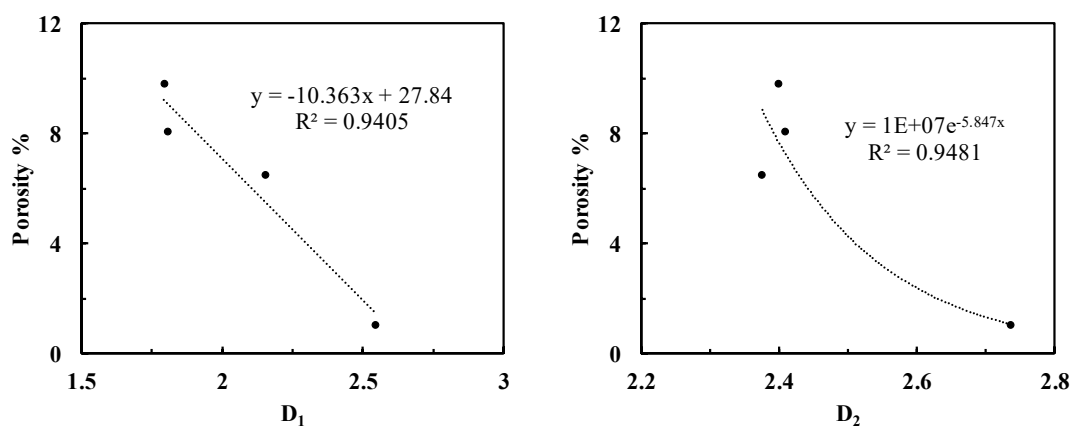

Figure 17. Relationship between porosity and fractal dimension of 3 sandstone samples and 1 mudstone sample. 
The fractal dimension decreases with the increasing porosity. It is reasonable as the increasing porosity usually means the increasing pore size, and therefore properties of core samples become better.

\subsubsection{Relationship between Fractal Dimension and Permeability}

The relationship between permeability and fractal dimension of three sandstone samples (Nos 53-54, 42 and 24) and one mudstone (No. 14) is shown in Figure 18. Similar to porosity, permeability is both negatively correlated to $D_{1}$ and $D_{2}$. Therefore, the calculated fractal dimension $D_{1}$ and $\mathrm{D}_{2}$ can be used for evaluating core properties.
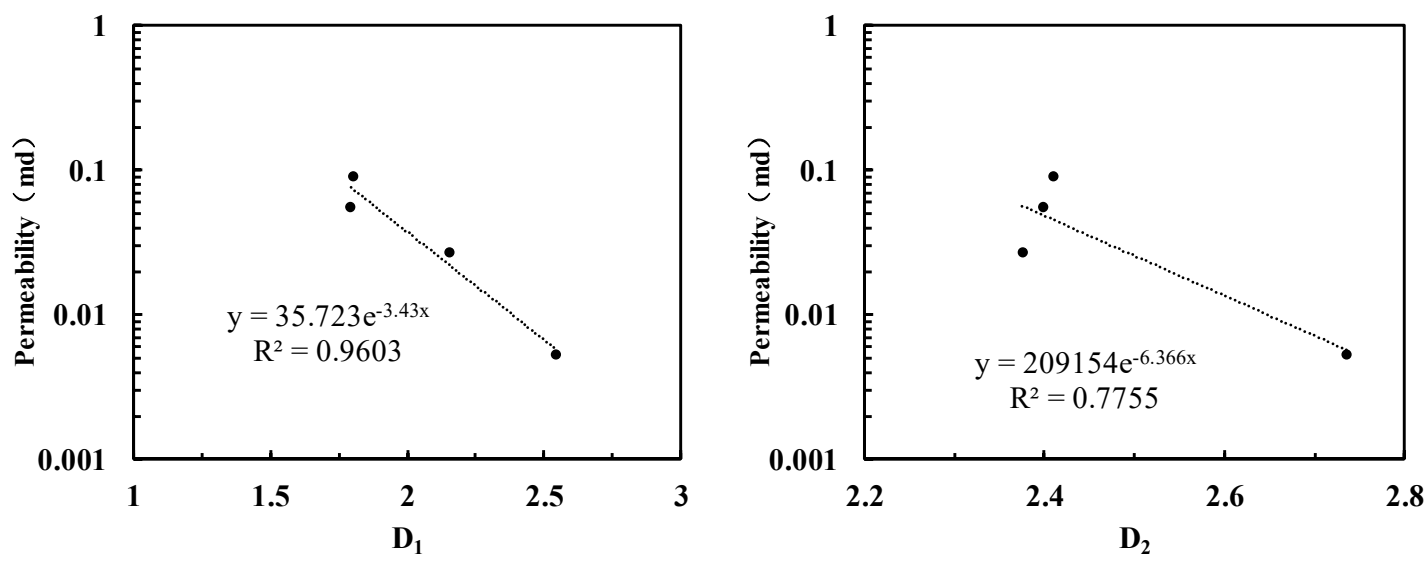

Figure 18. Relationship between fractal dimension and permeability of 3 sandstone samples and 1 mudstone sample.

\section{Conclusions}

Characteristics of nanopore structure in shale, tight sandstone and mudstone have been studied with nitrogen adsorption experiment and fractal theory. Several conclusions could be drawn as follows:

(1) The morphologies of nitrogen adsorption-desorption curves of 10 shale samples belong to the $\mathrm{H} 2$ and $\mathrm{H} 3$ types according to IUPAC isotherm classification standard, while the curve of nitrogen adsorption-desorption of three sandstone sample is closer to H3 type.

(2) The pore sizes of the shale have certain heterogeneity, and the pore size intervals are mainly concentrated less than $30 \mathrm{~nm}$, with at least a relatively obvious peak value distributed around $3 \mathrm{~nm}-10 \mathrm{~nm}$.

(3) BET specific surface area of sandstone is smaller than that of shale, and the pore volume and average pore diameter are much larger than those in shale. The BET specific surface area of mudstone is much larger than that of sandstone, and the pore volume and average diameter are much smaller than those in sandstone.

(4) The larger the average pore size of sandstone is, the smaller the BET specific surface area will be, and the BET specific surface area decreases with the increase of permeability. With the increase of porosity and permeability, BET specific surface area decreases with the increasing average pore size.

(5) Fractal dimensions calculated from the low relative pressure range $D_{1}$ are generally less than those calculated from the high relative pressure range $D_{2} . D_{1}$ reflects the surface roughness of pore structures and $D_{2}$ quantifies the spatial irregularity of pore spaces, and $D_{1}$ and $D_{2}$ are negatively correlated with each other. Compared with $\mathrm{D}_{1}, \mathrm{D}_{2}$ has stronger relationships with pore structure parameters and core properties. With $\mathrm{D}_{2}$ increases, $\mathrm{BET}$ specific surface area increases but average pore diameter, porosity and permeability decreases.

Author Contributions: Experiment and Methodology, X.L., Z.G. and C.R.; Writing-Original Draft Preparation, S.F.; Writing-Review \& Editing, K.Y.; Data Analysis \& Editing, F.W. 
Funding: This work was supported by the National Science and Technology Major Project (No. 2017ZX05001-001), National Natural Science Foundation of China (Nos. 51604285 and 51874320) and Scientific Research Foundation of China University of Petroleum, Beijing (No. 2462017BJB11).

Conflicts of Interest: The authors declare no conflict of interest.

\section{References}

1. Gasparik, M.; Ghanizadeh, A.; Bertier, P.; Gensterblum, Y.; Bouw, S.; Krooss, B.M. High-Pressure Methane Sorption Isotherms of Black Shales from The Netherlands. Energy Fuels 2012, 26, 4995-5004. [CrossRef]

2. Loucks, R.G.; Ruppel, S.C. Mississippian Barnett Shale: Lithofacies and depositional setting of a deep-water shale-gas succession in the Fort Worth Basin, Texas. AAPG Bull. 2007, 91, 579-601. [CrossRef]

3. Loucks, R.G.; Reed, R.M.; Ruppel, S.C.; Jarvie, D.M. Morphology, Genesis, and Distribution of Nanometer-Scale Pores in Siliceous Mudstones of the Mississippian Barnett Shale. J. Sediment. Res. 2009, 79, 848-861. [CrossRef]

4. Wang, F.; Lian, P.; Jiao, L.; Liu, Z.; Zhao, J. Fractal analysis of microscale and nanoscale pore structures in carbonates using high-pressure mercury intrusion. Geofluids 2018, 2018, 1840017. [CrossRef]

5. Wang, F.; Yang, K.; Cai, J. Fractal characterization of tight oil reservoir pore structure using nuclear magnetic resonance and mercury intrusion porosimetry. Fractals 2018, 26, 1840017. [CrossRef]

6. Ross, D.J.K.; Marc Bustin, R. The importance of shale composition and pore structure upon gas storage potential of shale gas reservoirs. Mar. Pet. Geol. 2009, 26, 916-927. [CrossRef]

7. Ghanbarian, B.; Torres-Verdín, C.; Lake, L.W.; Marder, M. Gas permeability in unconventional tight sandstones: Scaling up from pore to core. J. Pet. Sci. Eng. 2019, 173, 1163-1172. [CrossRef]

8. Chen, K.; Zhang, T.; Chen, X.; He, Y.; Liang, X. Model construction of micro-pores in shale: A case study of Silurian Longmaxi Formation shale in Dianqianbei area, SW China. Pet. Explor. Dev. 2018, 45, $412-421$. [CrossRef]

9. Millán, H.; Govea-Alcaide, E.; García-Fornaris, I. Truncated fractal modeling of H2O-vapor adsorption isotherms. Geoderma 2013, 206, 14-23. [CrossRef]

10. Yang, Y.; Wu, K.; Zhang, T.; Xue, M. Characterization of the pore system in an over-mature marine shale reservoir: A case study of a successful shale gas well in Southern Sichuan Basin, China. Petroleum 2015, 1, 173-186. [CrossRef]

11. Wang, F.; Jiao, L.; Liu, Z.; Tan, X.; Wang, C.; Gao, J. Fractal Analysis of Pore Structures in Low Permeability Sandstones Using Mercury Intrusion Porosimetry. J. Porous Media 2018, 21, 1097-1119. [CrossRef]

12. Ming, M.; Guojun, C.; Yong, X.; Shijun, H.; Chengfu, L.; Lianhua, X. Fractal characteristics of pore structure of continental shale in the process of thermal evolution. Coal Geol. Explor. 2017, 45, 41-47.

13. Xiong, J.; Liu, X.; Liang, L. An Investigation of Fractal Characteristics of Marine Shales in the Southern China from Nitrogen Adsorption Data. J. Chem. 2015, 2015, 303164. [CrossRef]

14. Shao, X.; Pang, X.; Li, Q.; Wang, P.; Chen, D.; Shen, W.; Zhao, Z. Pore structure and fractal characteristics of organic-rich shales: A case study of the lower Silurian Longmaxi shales in the Sichuan Basin, SW China. Mar. Pet. Geol. 2017, 80, 192-202. [CrossRef]

15. Li, A.; Ding, W.; He, J.; Dai, P.; Yin, S.; Xie, F. Investigation of pore structure and fractal characteristics of organic-rich shale reservoirs: A case study of Lower Cambrian Qiongzhusi formation in Malong block of eastern Yunnan Province, South China. Mar. Pet. Geol. 2016, 70, 46-57. [CrossRef]

16. Barrett, E.P.; Joyner, L.G.; Halenda, P.P. The Determination of Pore Volume and Area Distributions in Porous Substances. I. Computations from Nitrogen Isotherms. J. Am. Chem. Soc. 1951, 73, 373-380. [CrossRef]

17. Jiang, F.; Chen, D.; Chen, J.; Li, Q.; Liu, Y.; Shao, X.; Hu, T.; Dai, J. Fractal Analysis of Shale Pore Structure of Continental Gas Shale Reservoir in the Ordos Basin, NW China. Energy Fuels 2016, 30, 4676-4689. [CrossRef]

18. Zhang, L.; Li, J.; Jia, D.U.; Zhao, Y.; Xie, C.; Tao, Z. Study on the adsorption phenomenon in shale with the combination of molecular dynamic simulation and fractal analysis. Fractals 2018, 26, 1840004. [CrossRef]

19. Brunauer, S.; Emmett, P.H.; Teller, E. Adsorption of Gases in Multimolecular Layers. J. Am. Chem. Soc. 1938, 60, 309-319. [CrossRef]

20. Wang, Y.; Zhu, Y.; Liu, S.; Zhang, R. Pore characterization and its impact on methane adsorption capacity for organic-rich marine shales. Fuel 2016, 181, 227-237. [CrossRef] 
21. Tian, H.; Pan, L.; Xiao, X.; Wilkins, R.W.T.; Meng, Z.; Huang, B. A preliminary study on the pore characterization of Lower Silurian black shales in the Chuandong Thrust Fold Belt, southwestern China using low pressure N2 adsorption and FE-SEM methods. Mar. Pet. Geol. 2013, 48, 8-19. [CrossRef]

22. De Boer, J.H.; Lippens, B.C.; Linsen, B.G.; Broekhoff, J.; Van den Heuvel, A.; Osinga, T.J. Thet-curve of multimolecular N2-adsorption. J. Colloid Interface Sci. 1966, 21, 405-414. [CrossRef]

23. Mishra, S.; Mendhe, V.A.; Varma, A.K.; Kamble, A.D.; Sharma, S.; Bannerjee, M.; Kalpana, M.S. Influence of organic and inorganic content on fractal dimensions of Barakar and Barren Measures shale gas reservoirs of Raniganj basin, India. J. Nat. Gas Sci. Eng. 2018, 49, 393-409. [CrossRef]

24. Sun, L.; Tuo, J.; Zhang, M.; Wu, C.; Wang, Z.; Zheng, Y. Formation and development of the pore structure in Chang 7 member oil-shale from Ordos Basin during organic matter evolution induced by hydrous pyrolysis. Fuel 2015, 158, 549-557. [CrossRef]

25. Horváth, G.; Kawazo, K. Method for The Calculation of Effective Pore Size Distribution in Molecular Sieve Carbon. J. Chem. Eng. Jpn. 1983, 16, 470-475. [CrossRef]

26. Seaton, N.A.; Walton, J. A new analysis method for the determination of the pore size distribution of porous carbons from nitrogen adsorption measurements. Carbon 1989, 27, 853-861. [CrossRef]

27. Liu, K.; Ostadhassan, M.; Kong, L. Multifractal characteristics of Longmaxi Shale pore structures by $\mathrm{N}_{2}$ adsorption: A model comparison. J. Pet. Sci. Eng. 2018, 168, 330-341. [CrossRef]

28. Cai, J.; Lin, D.; Singh, H.; Wei, W.; Zhou, S. Shale gas transport model in 3D fractal porous media with variable pore sizes. Mar. Pet. Geol. 2018, 98, 437-447. [CrossRef]

29. Xia, Y.; Cai, J.; Wei, W.; Hu, X.; Wang, X.; Ge, X. A new method for calculating fractal dimensions of porous media based on pore size distribution. Fractals 2018, 26, 1850006. [CrossRef]

30. Cai, J.; Wei, W.; Hu, X.; Liu, R.; Wang, J. Fractal characterization of dynamic fracture network extension in porous media. Fractals 2017, 25, 17500232. [CrossRef]

31. Wang, F.; Jiao, L.; Lian, P.; Zeng, J. Apparent gas permeability, intrinsic permeability and liquid permeability of fractal porous media: Carbonate rock study with experiments and mathematical modelling. J. Pet. Sci. Eng. 2019, 173, 1304-1315. [CrossRef]

32. Pfeifer, P.; Avnir, D. Chemistry in noninteger dimensions between two and three. I. Fractal theory of heterogeneous surfaces. J. Chem. Phys. 1983, 79, 3558-3565. [CrossRef]

33. Hinai, A.A.; Rezaee, R.; Esteban, L.; Labani, M. Comparisons of pore size distribution: A case from the Western Australian gas shale formations. J. Unconv. Oil Gas Resour. 2014, 8, 1-13. [CrossRef]

34. Sun, Z.; Zhang, H.; Wei, Z.; Wang, Y.; Wu, B.; Zhuo, S.; Zhao, Z.; Li, J.; Hao, L.; Yang, H. Effects of slick water fracturing fluid on pore structure and adsorption characteristics of shale reservoir rocks. J. Nat. Gas Sci. Eng. 2018, 51, 27-36. [CrossRef]

35. Ghanbarian, B.; Daigle, H. Fractal dimension of soil fragment mass-size distribution: A critical analysis. Geoderma 2015, 245-246, 98-103. [CrossRef]

36. Ghanbarian-Alavijeh, B.; Hunt, A.G. Comments on "More general capillary pressure and relative permeability models from fractal geometry" by Kewen Li. J. Contam. Hydrol. 2012, 140, 21-23. [CrossRef] [PubMed]

(C) 2019 by the authors. Licensee MDPI, Basel, Switzerland. This article is an open access article distributed under the terms and conditions of the Creative Commons Attribution (CC BY) license (http://creativecommons.org/licenses/by/4.0/). 